\title{
Rapid Biodiesel Fuel Production Using Novel Fibrous Catalyst Synthesized by Radiation-Induced Graft Polymerization
}

\author{
Yuji Ueki $^{{ }^{*}}$, Nor Hasimah Mohamed ${ }^{2,3}$, Noriaki Seko ${ }^{1}$, Masao Tamada ${ }^{1,3}$ \\ ${ }^{1}$ Environment and Industrial Materials Research Division, Quantum Beam Science Directorate, \\ Japan Atomic Energy Agency, Takasaki, Japan \\ ${ }^{2}$ Radiation Processing Technology Division, Malaysian Nuclear Agency, Selangor, Malaysia \\ ${ }^{3}$ Department of Chemistry and Chemical Biology, Graduate School of Engineering, Gunma University, Kiryu, Japan \\ E-mail: ueki.yuji@jaea.go.jp
}

Received March 30, 2011; revised April 25, 2011: accepted May 16, 2011

\begin{abstract}
An efficient fibrous catalyst for the biodiesel fuel production has been synthesized by radiation-induced graft polymerization of 4-chloromethylstyrene onto a nonwoven polyethylene (NWPE) fabric followed by amination with trimethylamine (TMA) and further treatment with $\mathrm{NaOH}$. The degree of grafting of NWPE fabric and TMA group density of fibrous catalyst could easily and reproducibly be controlled within a range of up to $340 \%$ and $3.6 \mathrm{mmol}-\mathrm{TMA} / \mathrm{g}$-catalyst, respectively. In the transesterification of triglycerides and ethanol using the synthesized fibrous catalyst, the conversion ratio of triglycerides reached $95 \%$ after $4 \mathrm{~h}$ reaction at $50^{\circ} \mathrm{C}$.
\end{abstract}

Keywords: Biomass, Biodiesel Fuel, Triglycerides, Heterogeneous Catalysis, Radiation-Induced Graft Polymerization, Renewable Resources

In order to deal with the future exhaustion of fossil fuels and growing international energy demand, numerous attempts to study and develop alternative fuels with renewability are underway in various parts of the world. Among others, biodiesel fuel (BDF), which is defined as the monoalkyl esters of fatty acids derived from triglycerides (TGs) by transesterification with alcohols, has been regarded as a promising alternative fuel over petroleum because of its qualities such as renewable resources (plant and animal), lower kinetic viscosity, and decrease in petrochemical dependence, green house effect and air pollution. The BDF production be classified into several methods according to the type of catalyst; acid- [1-3], alkali- [1,4-6], lipase- [7,8], and metal oxide-catalyzed method $[9,10]$ and non-catalytic supercritical methanol method [11-13]. Some methods of industrial production of BDF from oil/fat have already been developed; and at present, an alkali catalyst method of using a homogeneous catalyst such as $\mathrm{NaOH}$ or $\mathrm{KOH}$ is in the mainstream due to faster reaction rates [1,4-6]. However, occurrence of undesired saponification and difficulty on the separation of homogenized catalyst from the reaction mixture are its weak points.

Recently, use of porous anion exchange resins was proposed by N. Shibasaki-Kitakawa et al., as a modification technique over the traditional alkali catalyst method $[14,15]$. According to the method of using such a porous anion exchange resin, the catalyst does not dissolve in the reaction system, and therefore a step of separating the catalyst is omitted. However, sample diffusion into the pores of the catalyst is rate-limiting since the catalyst has a reaction site inside the pores. Accordingly, the reaction speed is slow; thus limiting its use in the mass-scale industrial production of $\mathrm{BDF}$.

Meanwhile, our team has developed a grafted polymer as an ion exchanger that secures high reaction speed and enables high-speed processing [16-18]. The grafted polymer was synthesized by a radiation-induced graft polymerization that combined the surface of the polymer substance (trunk polymer) with another polymer chain (graft chain). Especially, our team has been intensively studying about the grafted polymers with a substrate of a fibrous polymer having a large specific surface area and having a high-level contact efficiency, and it has found 
that its adsorption rate was $10-100$ times higher than that of conventional granular resins with respect to the metal absorption. Therefore, it is expected that this feature of the grafted fibrous polymer can lead to the high-efficiency BDF production as in the case of the metal adsorption. In the present paper, the applicability of the grafted fibrous polymer to BDF production has been investigated in lab-scale.

Fibrous catalyst for BDF production was synthesized by combination of a pre-irradiation grafting method and an emulsion graft polymerization technique, in a manner similar to our previous paper [16-18]. Nonwoven polyethylene (NWPE) fabric, of which the fiber diameter was $13 \mu \mathrm{m}$, was used as a trunk polymer for grafting. The NWPE fabric was irradiated with an electron beam up to $100 \mathrm{kGy}$ in nitrogen atmosphere at dry-ice temperature, and the irradiated NWPE fabric was reacted with a monomer emulsion, which was composed of 4-chloro methylstyrene (CMS), polysorbate 20 (Tween 20) and deionized water, in a deaerated glass ampoule for $4 \mathrm{~h}$ at $40^{\circ} \mathrm{C}$. The monomer emulsion was bubbled with nitrogen gas to eliminate dissolved oxygen in the monomer emulsion, before using. After grafting, the grafted fabric was treated with $0.5 \mathrm{M}$ trimethylamine (TMA) at $50^{\circ} \mathrm{C}$ to introduce quaternary ammonium groups into the CMS-graft chains, and then the resultant fabric was further treated with $1 \mathrm{M} \mathrm{NaOH}$ to replace $\mathrm{Cl}^{-}$with $\mathrm{OH}^{-}$ before using. The degree of grafting (Dg) was defined by the following equation;

$$
\text { Degree of grafting: } \operatorname{Dg}[\%]=\left(W_{1}-W_{0}\right) / W_{0} \times 100
$$

where $W_{0}$ and $W_{1}$ are the dry weights of the NWPE fabric before and after grafting, respectively. The TMA group density of the resulting catalyst was estimated by the analysis of their nitrogen content using elemental analyzer.

As a result of trial and error, it was found that the CMS-grafted NWPE fabric with enough Dg (over 100\%) to use as a catalyst precursor was synthesized when the pre-irradiation dose was more than $20 \mathrm{kGy}$, the CMS concentration was $3 \mathrm{wt} \%$, and the weight ratio of CMS to Tween 20 was 10 to 1 , respectively. Under these optimum grafting conditions, the grafted CMS chain onto NWPE fabric could be easily and reproducibly controlled within a range of up to $340 \%$ (5.1 mmol-CMS/g-fabric), as shown in Figure 1. Furthermore, after detailed studies of the amination of the CMS-grafted NWPE fabric, it was also found that the amination was finished within 30 min, regardless of the $\mathrm{Dg}$. The degree of amination reached over $85 \%$, and the TMA group densities were 2.7, 3.3 and 3.6 mmol-TMA/g-catalyst for the $\mathrm{Dg}$ of $100 \%, 200 \%$ and $300 \%$, respectively. These TMA group densities are comparable to that of commercial granular

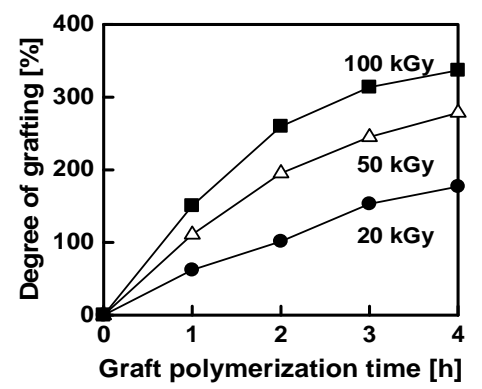

Figure 1. Effect of pre-irradiation dose on Dg of CMS onto NWPE fabric.

anion exchange resin (DIAION PA306S: 3.4 mmolTMA/g-resin, particle size: 150 - $425 \mu \mathrm{m})$, which was purchased from Mitsubishi Chemical Co.

To confirm the introduction of CMS-graft chain and TMA groups onto the NWPE fabric, the individual chemical structures of the NWPE fabric, CMS-grafted fabric and fibrous catalyst were examined using an ATRFTIR spectrometer. After grafting, the CMS-grafted fabric shows new characteristic peaks; the peaks at 1264 , 816 and $670 \mathrm{~cm}^{-1}$ were ascribed to $\mathrm{C}-\mathrm{Cl}$ stretching vibration of a chloromethyl group $[19,20]$ and the peaks at 1611,1511 and $1421 \mathrm{~cm}^{-1}$ were ascribed to aromatic ring. The intensity of the CMS-derived bands gradually increased with the increase in graft polymerization time, indicating that more CMS were introduced onto the surface of the NWPE fabric; that is, the CMS-grafted chain grew longer with time. After amination, new characteristic peaks at 1485 and $1222 \mathrm{~cm}^{-1}$, that were attributed to quaternary ammonium cations [21,22] and symmetric C-N stretching vibration [23], appeared in spectrum of the fibrous catalyst, and yet at the same time the strong peaks derived from $\mathrm{C}-\mathrm{Cl}$ bond disappeared.

The catalytic performance of the synthesized fibrous catalyst was evaluated through the transesterification of triolein (purity: 60\%) and ethanol, and the transesterification test was conducted in batch mode. The transesterification was performed by adding the pretreated fibrous catalyst with $\mathrm{NaOH}$ (catalyst weight: $0.5 \mathrm{~g}$, TMA group density: $3.5 \mathrm{mmol}-\mathrm{TMA} / \mathrm{g}$-catalyst) in a homogenous reaction solution (triolein: $2.8 \mathrm{~g}$, ethanol: $7.2 \mathrm{~g}$, decane as a cosolvent: $10.0 \mathrm{~g}$ ) at $50^{\circ} \mathrm{C}$. The TGs and BDF concentration in the reaction solution were measured by using high performance liquid chromatography system, in a similar manner to the method described by M. Holčapek, et al. [24]. As shown in Figure 2, the TGs, of which the chromatographic peaks appeared at $21-24 \mathrm{~min}$, were consumed with the lapse of reaction time, and on the other hand the BDF, of which the chromatographic peaks appeared at 11 - $14 \mathrm{~min}$, were gradually produced. These results confirm that the synthesized fibrous material functions as a catalyst for BDF production. The conver- 
sion ratio of TGs in different reaction times reached $23 \%$, $48 \%, 70 \%, 82 \%$, and $95 \%$ at $10 \mathrm{~min}, 30 \mathrm{~min}, 1 \mathrm{~h}, 2 \mathrm{~h}$, and $4 \mathrm{~h}$, respectively. TGs in Figure 2 are specifically noted; and the conversion ratio of TGs relative to the reaction time is plotted as Figure 3 where the data with DIAION PA306S are also included for comparison. The fibrous catalyst promoted the transesterification at a reaction speed higher by at least 3 times than that with the granular resin. This is because the fibrous catalyst comprised fibers with specific shape. It is noteworthy that conversion ratio of TGs in a reaction time of $2 \mathrm{~h}$ was $82 \%$ with the fibrous catalyst and $26 \%$ with the granular resin.

In addition, the influence of the type of alcohol on BDF production was investigated. In this experiment, primary alcohols having different alkyl chain lengths, such as methanol, ethanol, 1-propanol, 1-butanol, 1-pentanol and 1-hexanol, were used; and the transesterification time was held constant at $2 \mathrm{~h}$. The other conditions were the same as in Figure 2. As in Figure 4, BDF was produced irrespective of the types of alcohol used, and it was found that the synthesized fibrous catalyst could be applicable to the transesterification of TGs with other various types of alcohols as well as ethanol. From the peaks of BDF in Figure 4, it was demonstrated a tendency that the alcohol having a longer alkyl chain length took a longer retention time. These differences in the retention time of each BDF represent the differences in the structure (hydrophobicity) of the produced BDF, and it was also found that different types of BDF could be produced from different types of alcohol. The conversion

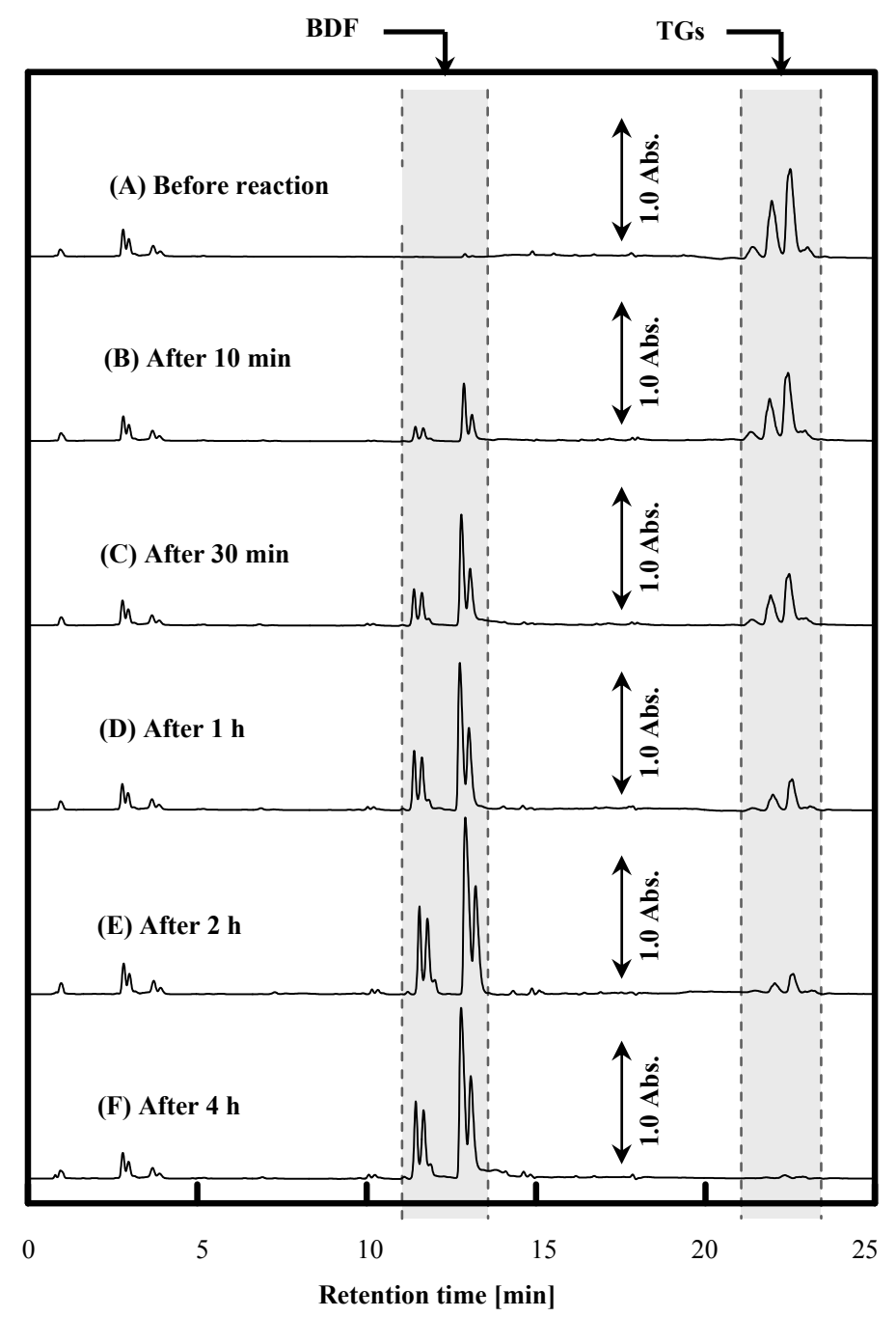

Figure 2. BDF production using the fibrous catalyst synthesized by radiation-induced graft polymerization. Sample: BDF solution (10 times dilution); injection volume: $5.0 \mu \mathrm{L}$; column: octadecyl bonded column (column size: $2.1 \mathrm{~mm}$ i.d. $\times 150 \mathrm{~mm}$ long, particle size: $5 \mu \mathrm{m})$; mobile phase: (A): water, (B): acetonitrile, (C): 2-propanol-hexane (5:4, v/v); flow rate: $0.5 \mathrm{~mL} / \mathrm{min}$; linear gradient: $30 \% \mathrm{~A}+70 \% \mathrm{~B}(0 \mathrm{~min}) \rightarrow 100 \% \mathrm{~B}(10 \mathrm{~min}) \rightarrow 50 \% \mathrm{~B}+50 \% \mathrm{C}(20 \mathrm{~min}) \rightarrow 50 \% \mathrm{~B}+50 \% \mathrm{C}(25 \mathrm{~min})$; column temperature: $40^{\circ} \mathrm{C}$; detection: $\mathrm{UV}$ absorption at $205 \mathrm{~nm}$. 


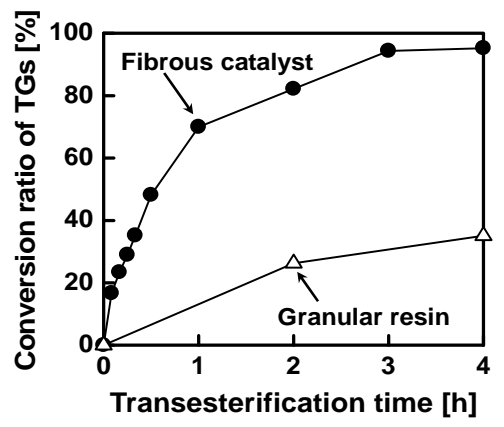

Figure 3. Comparison of catalytic performance of fibrous catalyst and granular resin for BDF production.

ratio of TGs in transesterification with different alcohols after the reaction time of $2 \mathrm{~h}$ was $48 \%$ with methanol, $82 \%$ with ethanol, $82 \%$ with 1-propanol, $89 \%$ with 1-butanol, 53\% with 1-pentanol and 44\% with 1-hexanol, respectively. The conversion ratio of 1-pentanol and 1-hexanol became lower than that of ethanol, 1-propano- land 1-butanol due to steric hindrance. On the other hand, for short-chain alcohol like methanol, phase separation occurred before and after experiment, even if the cosolvent such as decane was added to uniformize the reaction solution. As a result, the conversion ratio of methanol was lower than that of ethanol, although the alkyl chain length of methanol was shorter. This phase separation might be attributed to the immiscibility between the TGs and methanol. To increase the miscibility of the two compounds, Tang et al. suggested that higher pressure and higher temperature are needed [25].

In conclusion, the fibrous catalyst for BDF production can be synthesized by radiation-induced graft polymerization, and it can produce BDF with faster and higher efficiency. This new kind of catalyst demonstrates strong potential in the acceleration of BDF production by offering and easy, efficient and reliable technique which eventually contributes on solving the current environmental issues.

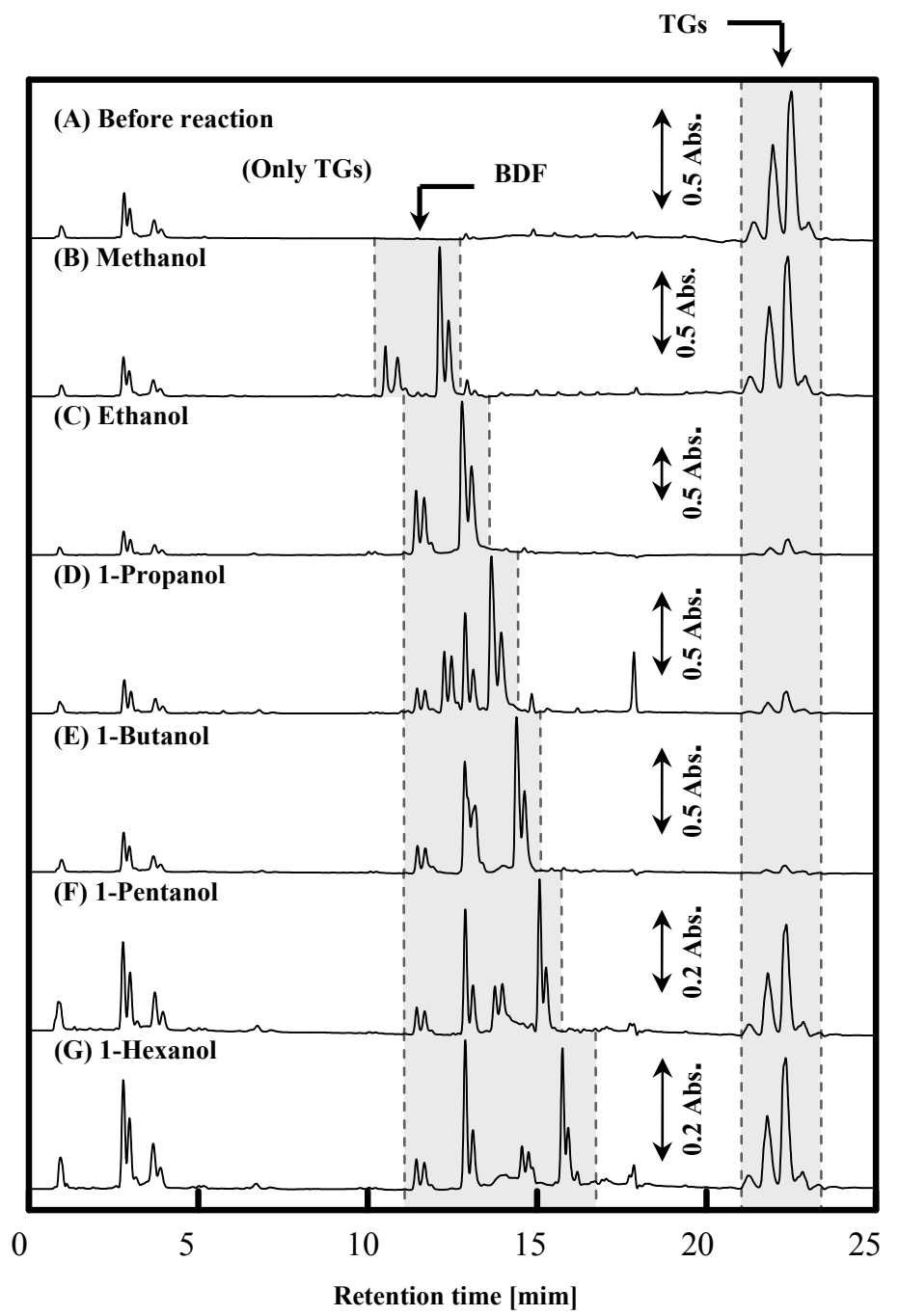

Figure 4. BDF production using the different types of the primary alcohols having different alkyl chain lengths. 


\section{References}

[1] B. Freedman, E. H. Pryde and T. L. Mounts, "Variables Affecting the Yields of Fatty Esters from Transesterified Vegetable Oils," Journal of American Oil Chemists' Society, Vol. 61, No. 10, 1984, pp. 1638-1643.

[2] M. D. Serio, R. Tesser, M. Dimiccoli, F. Cammarota, M. Nastasi and E. Santacesaria, "Synthesis of Biodiesel via Homogeneous Lewis Acid Catalyst," Journal of Molecular Catalysis A: Chemistry, Vol. 239, No. 1-2, 2005, pp. 111-115. doi:10.1016/i.molcata.2005.05.041

[3] G. Guan, K. Kusakabe, N. Sakurai and K. Moriyama, "Transesterification of Vegetable Oil to Biodiesel Fuel Using Acid Catalysts in the Presence of Dimethyl Ether," Fuel, Vol. 88, No. 1, 2009, pp. 81-86. doi:10.1016/j.fuel.2008.07.021

[4] F. R. Ma and M. A. Hanna, "Biodiesel Production: A Review," Bioresource Technology, Vol. 70, No. 1, 1999, pp. 1-15. doi:10.1016/S0960-8524(99)00025-5

[5] D. E. López, J. G. Goodwin Jr., D. A. Bruce and E. Lotero, "Transesterification of Triacetin with Methanol on Solid Acid and Base Catalysts," Applied Catalysis A, Vol. 295, No. 2, 2005, pp. 97-105.

[6] J. M. Dias, M. C. M. Alvim-Ferraz and M. F. Almeida, "Comparison of the Performance of Different Homogeneous Alkali Catalysts during Transesterification of Waste and Virgin Oils and Evaluation of Biodiesel Quality," Fuel, Vol. 87, No. 17-18, 2008, pp. 3572-3578. doi:10.1016/j.fuel.2008.06.014

[7] M. Mittelbach, "Lipase Catalyzed Alcoholysis of Sunflower Oil," Journal of American Oil Chemists' Society, Vol. 67, No. 3, 1990, pp. 168-170.

[8] A. Bajaj, P. Lohan, P. N. Jha and R. Mehrotra, "Biodiesel Production through Lipase Catalyzed Transesterification: An Overview," Journal of Molecular Catalysis B: Enzymatic, Vol. 62, No. 1, 2010, pp. 9-14.

doi:10.1016/i.molcatb.2009.09.018

[9] O. S. Stamenković, V. B. Veljković, Z. B. Todorović, M. L. Lazić, I. B. Banković-Ilić and D. U. Skala, "Modeling the Kinetics of Calcium Hydroxide Catalyzed Methanolysis of Sunflower Oil," Bioresource Technology, Vol. 101, No. 12, 2010, pp. 4423-4430. doi:10.1016/j.biortech.2010.01.109

[10] Z. Wen, X. Yu, S.-T. Tu, J. Yan and E. Dahlquist, "Synthesis of Biodiesel from Vegetable Oil with Methanol Catalyzed by Li-Doped Magnesium Oxide Catalysts," Applied Energy, Vol. 87, No. 3, 2010, pp. 743-748. doi:10.1016/j.apenergy.2009.09.013

[11] S. Saka and D. Kusdiana, "Biodiesel Fuel from Rapeseed Oil as Prepared in Supercritical Methanol," Fuel, Vol. 80, No. 2, 2001, pp. 225-231. doi:10.1016/S0016-2361(00)00083-1

[12] D. Kusdiana and S. Saka, "Two-Step Preparation for Catalyst-Free Biodiesel Fuel Production. Hydrolysis and Methyl Esterification," Applied Biochemistry and Biotechnology, Vol. 115, No. 1-3, 2004, pp. 781-791. doi:10.1385/ABAB:115:1-3:0781
[13] S. Saka, Y. Isayama, Z. Ilham and X. Jiayu, "New Process for Catalyst-Free Biodiesel Production Using Subcritical Acetic Acid and Supercritical Methanol," Fuel, Vol. 89, No. 7, 2010, pp. 1442-1446.

doi:10.1016/j.fuel.2009.10.018

[14] T. Yonemoto, N. Kitakawa and T. Toda, "Method for Producing Fatty Acid Ester," Japan Kokai Tokkyo Koho, 2006, Article ID: 2006-104316, pp. 1-14.

[15] N. Shibasaki-Kitakawa, H. Honda, H. Kuribayashi, T. Toda, T. Fukumura and T. Yonemoto, "Biodiesel Production Using Anionic Ion-Exchange Resin as Heterogeneous Catalyst," Bioresource Technology, Vol. 98, No. 2, 2007, pp. 416-421. doi:10.1016/j.biortech.2005.12.010

[16] A. Sekine, N. Seko, M. Tamada and Y. Suzuki, "Biodegradable Metal Adsorbent Synthesized by Graft Polymerization onto Nonwoven Cotton Fabric," Radiation Physics and Chemistry, Vol. 79, No. 1, 2010, pp. 16-21. doi:10.1016/j.radphyschem.2009.08.007

[17] T. Takeda, M. Tamada, N. Seko and Y. Ueki, "Ion Exchange Fabric Synthesized by Graft Polymerization and Its Application to Ultra-Pure Water Production," Radiation Physics and Chemistry, Vol. 79, No. 3, 2010, pp. 223-226. doi:10.1016/j.radphyschem.2009.08.042

[18] L. D. C. Nayanajith, Y. Ueki, N. Seko, H. Hoshina and M. Tamada, "Aminated Adsorbent Synthesized by Radiation-Induced Graft Polymerization of 4-Chloromethylstyrene onto Nonwoven Polylactic Acid Fabric and Its Adsorption Capacity for Metal Ions," Journal of Ion EXchange, Vol. 21, No. 3, 2010, pp. 123-126.

[19] B.-B. Jang, K.-P. Lee, D.-H. Min and J. Suh, "Immobile Artificial Metalloproteinase Containing Both Catalytic and Binding Groups," Journal of American Oil Chemists' Society, Vol. 120, No. 46, 1998, pp. 12008-12016.

[20] D. W. Jenkins and S. M. Hudson, "Heterogeneous Graft Copolymerization of Chitosan Powder with Methyl Acrylate Using Trichloroacetyl-Manganese Carbonyl Co-Initiation," Macromolecules, Vol. 35, No. 9, 2002, pp. 3413-3419. doi:10.1021/ma011336b

[21] D. Portehault, C. Giordano, C. Sanchez and M. Antonietti, "Nonaqueous Route toward a Nanostructured Hybrid Titanate," Chemistry of Materials, Vol. 22, No. 6, 2010, pp. 2125-2131. doi:10.1021/cm903709m

[22] K. W. Hipps and U. Mazur, "Vibrational and Low-Lying Electronic Transitions in Tetraalkylammonium Salts of $\mathrm{CoBr}_{4}^{2-}, \mathrm{CoCl}_{4}^{2-}$, and $\mathrm{Co}(\mathrm{CNS})_{4}^{2-}$ as observed by Raman, Infrared, and Tunneling Spectroscopies," The Journal of Physical Chemistry, Vol. 91, No. 20, 1987, pp. 5218-5224. doi:10.1021/j100304a017

[23] M.-I. Boyer, S. Quillard, E. Rebourt, G. Louarn, J. P. Buisson, A. Monkman and S. Lefrant, "Vibrational Analysis of Polyaniline: A Model Compound Approach," The Journal of Physical Chemistry B, Vol. 102, No. 38, 1998, pp. 7382-7392. doi:10.1021/jp972652o

[24] M. Holčapek, P. Jandera, J. Fischer and B. Prokeš, “Analytical Monitoring of the Production of Biodiesel by High-Performance Liquid Chromatography with Various Detection Methods," Journal of Chromatography A, Vol. 858, No. 1, 1999, pp. 13-31. 
doi:10.1016/S0021-9673(99)00790-6

[25] Z. Tang, Z. Du, E. Min, L. Gao, T. Jiang and B. Han, "Phase Equilibria of Methanol-Triolein System at Ele- vated Temperature and Pressure," Fluid Phase Equilibria, Vol. 239, No. 1, 2006, pp. 8-11.

doi:10.1016/j.fluid.2005.10.010 